\title{
ATENÇÃO DE ENFERMAGEM GINECOLÓGICA À COMUNIDADE TRANSGÊNERO PROMOVENDO A EQUIDADE: REVISÃO INTEGRATIVA
}

\section{ARTIGO DE REVISÃO}

GUEDES, Bárbara Adriana ${ }^{1}$

SKROCH, Sara da Silva ${ }^{2}$

SOUZA, Cristiane de ${ }^{3}$

LIBERATTO, Patrícia Amorim ${ }^{4}$

SALVATTI, Samantha Sofia Boldino ${ }^{5}$

PEDRO, Deyse Lisowski ${ }^{6}$

BARROS, Fabiane Frigotto de ${ }^{7}$

FRANCO, Adriana Cristina ${ }^{8}$

GUEDES, Bárbara Adriana. Et al. Atenção de enfermagem ginecológica à comunidade transgênero promovendo a equidade: Revisão integrativa. Revista Científica Multidisciplinar Núcleo do Conhecimento. Ano 05, Ed. 12, Vol. 18, pp. 78-

\footnotetext{
${ }^{1}$ Graduanda de Enfermagem das Faculdades Pequeno Príncipe.

2 Graduanda de Enfermagem.

${ }^{3}$ Graduanda de Enfermagem.

${ }^{4}$ Graduanda de Enfermagem.

${ }^{5}$ Graduanda de Enfermagem.

${ }^{6}$ Graduanda de Enfermagem.

7 Orientadora. Mestrado em Ensino Em Ciências Da Saúde.

${ }^{8}$ Orientadora. Mestrado em Ensino Em Ciências Da Saúde.
} 
100. Dezembro de 2020. ISSN: 2448-0959, Link de acesso: https://www.nucleodoconhecimento.com.br/saude/enfermagem-ginecologica

\section{RESUMO}

O estudo, originado da ânsia em desmitificar a realidade dos pacientes transgênero, objetiva desvelar a implementação da equidade na atenção ginecológica para essa comunidade, elencando Diagnósticos de Enfermagem através da Taxonomia NANDA 2018/2020 e CIPE. Trata-se de revisão integrativa, articulada à metodologia da problematização de Maguerez, utilizando as bases de dados Google Acadêmico e SciELO. Foram critérios de inclusão: gratuidade, publicação de até 5 anos, língua portuguesa ou inglesa, pertinência temática, sendo eleitos 22 artigos para a amostra, que abordaram adversidades vivenciadas pelo público foco e dificuldades em oferecer assistência de enfermagem equânime e de excelência, enfatizando a dificuldade de manejo e desrespeito aos direitos desses usuários. Confirmou-se a pouca produção de artigos sobre a temática, além da urgente capacitação com relação às diferentes e legítimas manifestações humanas. Sua análise contribui para a construção do conhecimento e influencia o processo despatologizador das questões de gênero.

Palavras-chave: transgênero e ginecologia, transgênero e equidade, enfermagem.

\section{INTRODUÇÃO}

Desde os primórdios da civilização humana, elencamos características dentro de um sistema binário, criado pelos modelos sociais, entre o que é feminino e masculino. Dentro dessa forma dicotômica de pensar, seres humanos sempre foram classificados entre homens e mulheres com base em suas genitálias e no comportamento social esperado para cada sexo. Em tal raciocínio, há os sexos feminino e masculino e o comportamento esperado de tais sexos biológicos conforme tradições culturais específicas, que se classificam como gênero, e essa tradição, esse conhecimento préconcebido do que é normal ou esperado, faz com que a sociedade tenha dificuldades em aceitar ou entender o fenômeno da transexualidade, e ainda mais, em reconhecer 
suas necessidades e peculiaridades no tocante ao atendimento de saúde, criando obstáculos e preconceitos. (GRANT, 2010)

Para entender a posição da enfermagem no tocante ao tratamento dos pacientes transexuais, atendendo às suas necessidades e expectativas dentro dos princípios de equidade e integralidade preconizados pelo SUS, antes de mais nada é necessário conhecer profundamente a respeito desse fenômeno e, principalmente, dessas pessoas para muito além do determinismo biológico. Entender suas motivações vitais, suas dúvidas e seus anseios.

Segundo Michaellis, Dicionário Brasileiro da Língua Portuguesa, 2015, transexual é aquele que revela transexualismo, ou ainda, quem se submeteu a tratamento de hormônios e procedimento cirúrgico a fim de adquirir características do sexo oposto; profunda inadequação ao próprio sexo, acompanhado pelo desejo de adquirir características físicas externas do sexo oposto, por meio de tratamento clínico e/ou procedimento cirúrgico.

Nessa tentativa simplista de explicar o termo, resta uma grave omissão acerca de seus significados sociais e antropológicos. Infelizmente a grande maioria dos teóricos ainda trata o fenômeno transexual como uma doença, ou transtorno sexual, esquecendo de levar em consideração as escolhas e os sentimentos pessoais agregados ao processo. (NICHOLSON, 2000)

A identidade de gênero, ou a identificação individual com determinado gênero, que pode corresponder ou não com o sexo atribuído após o nascimento deve ser observada em todos os seus aspectos, biopsicossociais, e não apenas às questões biológicas, e ir ao encontro do reconhecimento do protagonismo de quem protagoniza essa realidade. Pessoas que lutam para serem reconhecidas socialmente como construções sociais e não como números de um código internacional de doenças. No entanto, as definições médicas, baseadas em manuais internacionais e em organizações internacionais, como os da OMS (Organização Mundial de Saúde), encontram ainda maior legitimidade no uso cotidiano destas para definirem suas vivências. 
Em contraponto aos determinantes técnicos e biológicos pode-se encontrar quem defenda o fenômeno com sensibilidade:

"Não se nasce mulher, torna-se. Nenhum dispositivo biológico, psíquico, ou econômico, define a figura que a fêmea humana tem na sociedade; é a civilização como um todo que elabora esse produto...que é chamado de feminino." (DE BEAUVOIR, 2011)

No tocante ao papel da Enfermagem, o Código de Ética dos Profissionais de Enfermagem ressalta, entre as responsabilidades e deveres do enfermeiro: prestar assistência de enfermagem sem discriminação de qualquer natureza, respeitando, reconhecendo e realizando ações que garantam o direito da de tomar decisões sobre sua saúde, tratamento, conforto e bem-estar e respeitar o pudor, a privacidade e a intimidade do ser humano em todo seu ciclo vital. (COFEN, 2017)

O que é ser Enfermeiro se não cuidar? E cuidar implica respeito e humanização, ainda que crenças pessoais levem esses profissionais ao estranhamento inicial, é sua obrigação ética, moral e legal, exercer a profissão de forma integral respeitando as pessoas e a legislação.

A Constituição Federal de 1988 preconiza em seu artigo $5^{\circ}$ que todos são iguais perante a Lei, sem distinção de qualquer natureza, e ainda, em seu artigo 196 diz que a saúde é direito de todos e dever do Estado, garantido mediante políticas sociais e econômicas que visem à redução do risco de doença e de outros agravos e ao acesso universal e igualitário às ações e serviços para sua promoção, proteção e recuperação. Dentro desse escopo legal não resta dúvida que não cabe aos profissionais de saúde fazerem qualquer juízo de valor sobre aqueles que são destinatários desse direito, mas cumprir o que a carta magna determina. (CONSTITUIÇÃO FEDERAL, 1988)

A Enfermagem foi criada como ciência a partir da primeira proposta, formulada por Florence Nightingale em 1950, de organizar pressupostos metodológicos, modelos e teorias acerca dos conhecimentos específicos a ela relacionados. Desde então a 
profissão vem incrementando seus saberes e competências sem nunca perder a essência que fundamentou sua origem: o cuidado (GEOVANINI, 1995). É justamente centrado nesse cuidado, e nas evidências científicas, que as ações em enfermagem devem se pautar, o que inclui abordagens para muito além da saúde, mas exige a inclusão de políticas públicas e educação permanente e continuada, tanto para preparar e capacitar esses profissionais, dentro de uma lógica de promoção ao acolher em vez de excluir, rompendo com a lógica dicotômica e discriminatória que ainda hoje permanece no Brasil, como para derrubar estigmas e preconceitos que envolvem todo o universo transgênero. (BRASIL, 2017)

\section{MÉTODO}

Para realização deste estudo, optou-se pela Metodologia da Problematização articulada ao método de Revisão Integrativa cujo caminho metodológico permite a síntese de conhecimentos através de uma sequência rigorosa de passos que devem ser realizados para que possa se obter os resultados do estudo. (MENDES; SILVEIRA e GALVÃO, 2019)

A revisão integrativa determina um conhecimento atual sobre uma temática específica que é conduzida de modo a identificar, analisar e sintetizar resultados sobre estudos, independentes e de temas específicos, dos quais podem ter resultados positivos e repercussão benéfica na qualidade. (SOUZA; SILVA e CARVALHO, 2010)

O Arco de Maguerez, por sua vez, é constituído de cinco etapas: a observação da realidade trata-se de uma participação ativa dos sujeitos, com um olhar atento à realidade, no qual o tema do estudo está inserido ou acontecendo na vida real, o que possibilita perceber quais são os aspectos que precisam ser desenvolvidos, trabalhados, revisados ou melhorados, aproximando os expectadores da realidade. Na segunda etapa, com base na observação da realidade, são selecionados os pontos chave do problema ou assunto em questão, são analisados os aspectos que precisam ser conhecidos e melhor compreendidos, para buscar uma resposta ao problema. (PRADO et al., 2012) 
A teorização é a terceira etapa do Arco de Maguerez na qual ocorre o questionamento sobre os mecanismos dos problemas e situações observadas, buscando compreender melhor os fatores que desencadeiam e agravam as diversas situações, tanto na teoria quanto na prática, e foi justamente nessa etapa em que se optou pelo incremento metodológico da revisão integrativa. A quarta etapa é a busca de hipóteses de solução viáveis, de maneira crítica e criativa, tendo em vista os problemas observados. A aplicação à realidade é a quinta etapa, onde há a construção de conhecimento, buscando transformar a realidade observada através das hipóteses anteriormente planejadas. (PRADO et al., 2012).

Figura 1- Fluxograma tipo prisma de elegibilidade dos artigos da fase de teorização

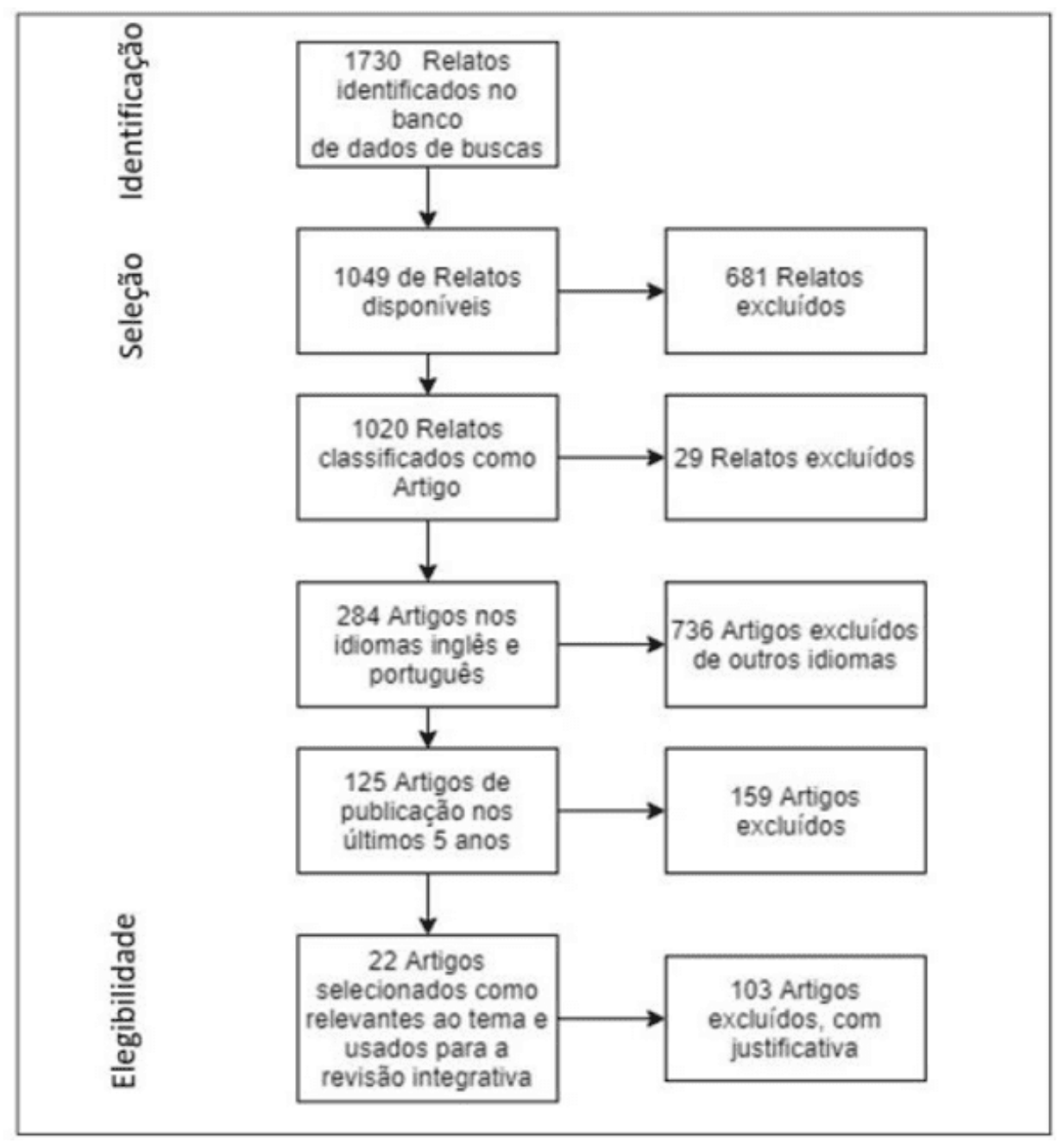

Fonte: As autoras, 2020. 


\section{RESULTADOS}

A articulação entre os dois métodos de pesquisa possibilitou uma análise de um caso pré-determinado e específico retirado do contexto da Atenção Básica de Saúde (ABS), a partir de uma consulta de enfermagem, ensejando a fonte inicial de questionamentos acerca da realidade vivida por essa comunidade e a análise dos conhecimentos dominados pelas equipes de enfermagem sobre a temática e da capacidade dessas mesmas equipes em oferecer atendimento equânime e de qualidade, respeitando a diversidade e peculiaridades do público atendido.

A seguir, são apresentados os resultados da revisão integrativa por meio de um quadro sinóptico que aponta as principais informações extraídas da amostra. 
Quadro 1 - Categorização da amostra da revisão integrativa quanto ao ano de publicação, método, periódico, resultados e recomendações

\begin{tabular}{|c|c|c|c|c|c|c|}
\hline ANO & AUTOR (s) & $\begin{array}{c}\text { TITULO DO } \\
\text { ARTIGO }\end{array}$ & MÉTODO & PERIÓDICO & RESULTADOS & RECOMENDAÇÖES \\
\hline 2015 & $\begin{array}{l}\text { MALIVER- } \\
\text { OBEDIN, J. }\end{array}$ & $\begin{array}{l}\text { Time for OBGYNs } \\
\text { to Care for People } \\
\text { of All Genders }\end{array}$ & $\begin{array}{l}\text { Descritivo, } \\
\text { transversal }\end{array}$ & $\begin{array}{l}\text { JOURNAL } \\
\text { WOMEN'S } \\
\text { HEALTH }\end{array}$ & 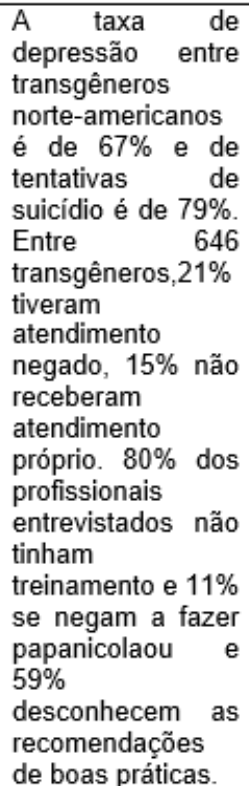 & $\begin{array}{l}\text { Realizar a assistência à } \\
\text { saúde de forma holística, } \\
\text { com qualidade e de } \\
\text { maneira integral. Utilizar } \\
\text { linguagem própria, dar } \\
\text { apoio social e realizar a } \\
\text { educação da população e } \\
\text { de profissionais da saúde. }\end{array}$ \\
\hline 2015 & $\begin{array}{l}\text { LIEBERT, } \\
\text { M. A. }\end{array}$ & $\begin{array}{l}\text { Care of the } \\
\text { Transgender } \\
\text { Patient: A Survey } \\
\text { of Gynecologists' } \\
\text { Current } \\
\text { Knowledge and } \\
\text { Practice }\end{array}$ & $\begin{array}{l}\text { Descritivo, } \\
\text { transversal }\end{array}$ & $\begin{array}{l}\text { JOURNAL } \\
\text { WOMEN'S } \\
\text { HEALTH }\end{array}$ & $\begin{array}{lr}\text { Dos } & 141 \\
\text { profissionais } & \text { de } \\
\text { ginecologia e e } & \\
\text { obstetrícia } 113 \text { não } \\
\text { receberam } \\
\text { treinamento para o } \\
\text { atendimento de } \\
\text { pacientes } \\
\text { transgêneros. } \\
35,3 \% \text { e } 29 \% \text { não } \\
\text { se sentem } \\
\text { confortáveis para } \\
\text { realizar } \\
\text { atendimento de } \\
\text { transgêneros } \\
\text { femininos } \\
\text { masculinos } \\
\text { respectivamente, a } \\
\text { maioria } \\
\text { conhecia não } \\
\text { recomendações } \\
\text { para o rastreio de } \\
\text { câncer de mama } \\
\text { em transgêneros }\end{array}$ & $\begin{array}{l}\text { Deve-se educar os } \\
\text { profissionais e futuros } \\
\text { profissionais sobre os } \\
\text { cuidados ginecológicos } \\
\text { para pessoas } \\
\text { transgêneros e diretrizes } \\
\text { devem ser publicadas para } \\
\text { auxiliar os profissionais }\end{array}$ \\
\hline 2015 & $\begin{array}{l}\text { PETRYA, A. } \\
\text { L. R. }\end{array}$ & 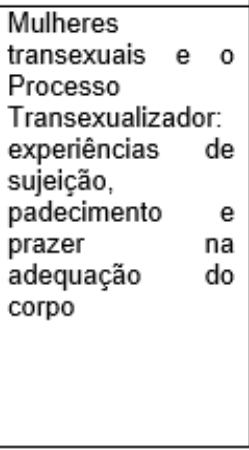 & $\begin{array}{l}\text { Pesquisa } \\
\text { exploratória } \\
\text { qualitativa }\end{array}$ & $\begin{array}{l}\text { Revista Gaúcha } \\
\text { de Enfermagem }\end{array}$ & 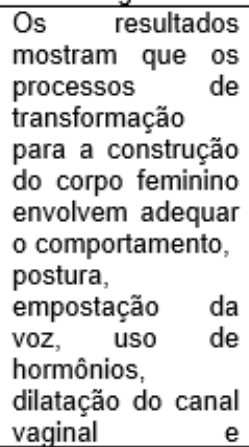 & $\begin{array}{l}\text { Promover a discussão que } \\
\text { envolve o Processo } \\
\text { Transexualizador, que traz } \\
\text { subsídios para a } \\
\text { enfermagem acerca das } \\
\text { modificações corporais } \\
\text { vivenciadas pelas } \\
\text { mulheres transexuais. }\end{array}$ \\
\hline
\end{tabular}




\begin{tabular}{|c|c|c|c|c|c|c|}
\hline & & & & & \begin{tabular}{lr}
\multicolumn{2}{l}{ complicações } \\
cirúrgicas. Tais \\
processos \\
sujeitam \\
o corpo a se \\
construir conforme \\
idealizado para \\
adequar-se a \\
identidade \\
gênero, \\
$\begin{array}{l}\text { infringindo-lhe } \\
\text { prazeres } \\
\text { padecimentos. }\end{array}$ \\
\end{tabular} & \\
\hline 2015 & $\begin{array}{l}\text { SPIZZIRRIL, } \\
\text { G. }\end{array}$ & $\begin{array}{l}\text { Aspectos } \\
\text { genéticos } \\
\text { relacionados ao } \\
\text { transexualismo }\end{array}$ & $\begin{array}{l}\text { Revisão } \\
\text { integrativa }\end{array}$ & 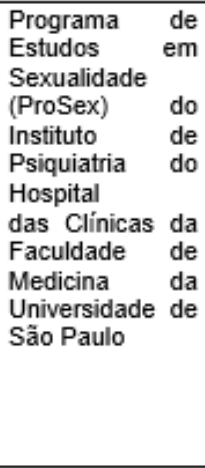 & $\begin{array}{l}\text { Constatou-se } \\
\text { probabilidade } \\
\text { desenvolvimento } \\
\text { do transexualismo } \\
\text { é maior } \\
\text { nos indivíduos } \\
\text { com genótipo } \\
\text { homozigoto para } \\
\text { alelos longos. }\end{array}$ & $\begin{array}{l}\text { Mais } \\
\text { pesquisas que estudem a } \\
\text { influência dos hormônios } \\
\text { antes, durante } \\
\text { ou após a gestação; a } \\
\text { variabilidade genética; os } \\
\text { fatores } \\
\text { ambientais; e as formas, } \\
\text { possivelmente, mas não } \\
\text { necessariamente, } \\
\text { que afetariam } \\
\text { determinadas estruturas } \\
\text { cerebrais são para } \\
\text { imprescindiveis } \\
\text { comporem } \\
\text { compreensão. }\end{array}$ \\
\hline 2016 & $\begin{array}{l}\text { SILVA, C. M. } \\
\text { C. } \\
\text { VARGENS, } \\
\text { O. M. C. }\end{array}$ & $\begin{array}{l}\text { Woman } \\
\text { experiencing } \\
\text { gynecologic } \\
\text { surgery: coping } \\
\text { with the changes } \\
\text { imposed by } \\
\text { surgery }\end{array}$ & $\begin{array}{l}\text { Pesquisa } \\
\text { exploratória } \\
\text { descritiva } \\
\text { qualitativa }\end{array}$ & $\begin{array}{l}\text { REVISTA } \\
\text { LATINOAMERIC } \\
\text { ANA D DE } \\
\text { ENFERMAGEM }\end{array}$ & $\begin{array}{l}\text { Quanto aos } \\
\text { sentimentos e } \\
\text { percepcóes } \\
\text { decorrentes da } \\
\text { cirurgia } \\
\text { ginecológica, este } \\
\text { estudo mostrou } \\
\text { que após algum } \\
\text { momento da } \\
\text { cirurgia, as } \\
\text { mulheres sobre o } \\
\text { refletiram sobm cirurgia } \\
\text { que a } \\
\text { significava e como } \\
\text { seriam suas vidas } \\
\text { a partir de então. }\end{array}$ & $\begin{array}{l}\text { Ao endereçar a mulher em } \\
\text { atendimento no contexto } \\
\text { de ginecologia cirurgia, o } \\
\text { enfermeiro deve ser capaz } \\
\text { de entender que fatores } \\
\text { individuais e socioculturais } \\
\text { interagem para formar o } \\
\text { Compreensão das } \\
\text { mulheres sobre o processo } \\
\text { experimentado } \\
\text { com cirurgia. Conhecendo } \\
\text { esses significados para ela } \\
\text { e para o } \\
\text { a maneira como ela } \\
\text { interpreta o que aconteceu } \\
\text { com ela é uma importante } \\
\text { ferramenta de cuidados. } \\
\text { Nessa perspectiva, } \\
\text { enfermeiro pode ser um } \\
\text { agente chave para ajudar } \\
\text { as mulheres a encontrar } \\
\text { seu próprio caminho para } \\
\text { superar as dificuldades } \\
\text { que eles enfrentam. }\end{array}$ \\
\hline 2016 & $\begin{array}{l}\text { BOUMAN, } \\
\text { M.B. SLUIS, } \\
\text { W. B. V. D. } \\
\text { HAMSTRA, } \\
\text { L. E. V. W. } \\
\text { BUNCAMPE } \\
\text { R. M. E. } \\
\text { KREUKELS, } \\
\text { B. P. C. } \\
\text { MEIJERINK, } \\
\text { W. J. H. J. } \\
\text { MULLENDE } \\
\text { R, M. G. }\end{array}$ & $\begin{array}{l}\text { Patient-Reported } \\
\text { Esthetic and } \\
\text { Functional } \\
\text { Outcomes of } \\
\text { Primary Total } \\
\text { Laparoscopic } \\
\text { Intestinal } \\
\text { Vaginoplasty in } \\
\text { Transgender } \\
\text { Women With } \\
\text { Penoscrotal } \\
\text { Hypoplasia }\end{array}$ & Descritivo & $\begin{array}{l}\text { THE } \\
\text { OOURNAL } \\
\text { MEDICINE } \\
\text { MEXUAL }\end{array}$ & $\begin{array}{l}\text { A satisfação dos } \\
\text { pacientes } \\
\text { transgêneros pós } \\
\text { cirurgia de } \\
\text { afirmação sexual } \\
\text { foi de média } 8 \\
\text { tendo como escala } \\
\text { de satisfação de } 0 \\
\text { a } 10 \text {, a satisfação } \\
\text { sobre a estética, } \\
\text { felicidade } \\
\text { desempenho e } \\
\text { sexual foi alta após } \\
\text { a cirurgia. }\end{array}$ & $\begin{array}{l}\text { Para os profissionais da } \\
\text { saúde, é necessário } \\
\text { buscar a satisfação } \\
\text { estética, funcional ea } \\
\text { sentimental nas mulheres } \\
\text { transgêneras pós cirurgia } \\
\text { de afirmação sexual, assim } \\
\text { como orientar e realizar } \\
\text { todos os cuidados pós } \\
\text { cirurgia. }\end{array}$ \\
\hline
\end{tabular}




\begin{tabular}{|c|c|c|c|c|c|c|}
\hline & $\begin{array}{l}\text { VARGENS, } \\
\text { O. M. C. }\end{array}$ & & & & \begin{tabular}{l|} 
é fria e impessoal. \\
Desejam maior \\
proximidade nesta \\
relação, pois é \\
com aquele \\
profissional que \\
serão tratados \\
assuntos íntimos e \\
pessoais. Esta \\
questão remete à \\
necessidade da \\
construção do \\
vínculo entre o \\
profissional \\
e a cliente.
\end{tabular} & $\begin{array}{l}\text { as premissas do modelo } \\
\text { humanizado, em que a } \\
\text { mulher } \\
\text { é o foco da atenção. } \\
\text { Assim, cabe ao } \\
\text { profissional adotar } \\
\text { estratégias, a fim de tornar } \\
\text { para a mulher a consulta } \\
\text { ginecológica um ambiente } \\
\text { mais acolhedor. }\end{array}$ \\
\hline 2017 & $\begin{array}{l}\text { Popadiuk, } \\
\text { G. S., } \\
\text { Oliveira, } \\
\text { D. C., \& }\end{array}$ & $\begin{array}{l}\text { A Política } \\
\text { Nacional de Saúde } \\
\text { Integral de } \\
\text { Lésbicas, Gays, } \\
\text { Bissexuais } \\
\text { e Transgêneros } \\
\text { (LGBT) e o acesso } \\
\text { ao Processo } \\
\text { Transexualizador } \\
\text { no Sistema Único } \\
\text { de Saúde (SUS): } \\
\text { avanços } \\
\text { desafios }\end{array}$ & $\begin{array}{l}\text { Pesquisa } \\
\text { exploratória } \\
\text { quanti/ } \\
\text { qualitativa. }\end{array}$ & $\begin{array}{lr}\text { Revista } & \text { Ciência } \\
\text { e } & \text { Saúde } \\
\text { coletiva. } & \\
\end{array}$ & 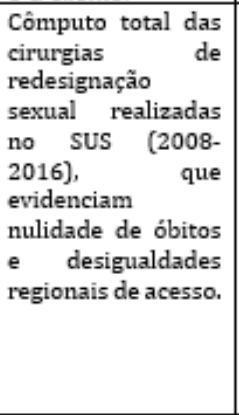 & $\begin{array}{l}\text { Envolvimento dos } \\
\text { movimentos sociais e do } \\
\text { controle social para } \\
\text { efetivação do respeito à } \\
\text { diversidade junto ao SUS }\end{array}$ \\
\hline 2017 & $\begin{array}{l}\text { ZAVLIN, } \\
\text { SCHAFF, J. } \\
\text { LELLE,, J. D. } \\
\text { JUBBAL, K. } \\
\text { T. } \\
\text { HERSCHBA } \\
\text { CH, P. } \\
\text { HENRICH, } \\
\text { G. } \\
\text { EHRENBER } \\
\text { GER, B. } \\
\text { KOVACS, L. } \\
\text { MACHENS, } \\
\text { H. G. } \\
\text { PAPADOPU } \\
\text { LOS, N. A. }\end{array}$ & $\begin{array}{l}\text { Male-to-Female } \\
\text { Sex Reassignment } \\
\text { Surgery using the } \\
\text { Combined } \\
\text { Vaginoplasty } \\
\text { Technique: } \\
\text { Satisfaction of } \\
\text { Transgender } \\
\text { Patients } \\
\text { Aesthetic, with } \\
\text { Functional, and } \\
\text { Sexual Outcomes }\end{array}$ & $\begin{array}{l}\text { Estudo } \\
\text { prospectivo } \\
\text { discritivo }\end{array}$ & Aesth Plast Surg & 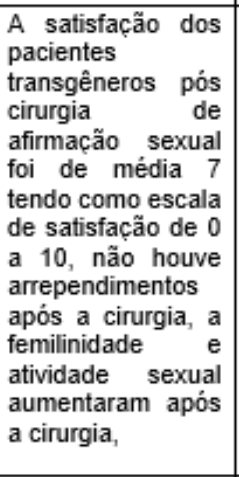 & $\begin{array}{l}\dot{E} \text { necessário realizar } \\
\text { cuidados após a cirurgia de } \\
\text { afirmação sexual e buscar } \\
\text { a satisfação do paciente } \\
\text { com a cirurgia. Criar } \\
\text { padrões para } \\
\text { questionários poderá } \\
\text { garantir uma melhor } \\
\text { evidência da qualidade da } \\
\text { pesquisa e cirurgias. }\end{array}$ \\
\hline 2017 & $\begin{array}{l}\text { HOOPER, } \\
\text { G. L. ATNIP, } \\
\text { S. O'DELL, } \\
\text { K. }\end{array}$ & $\begin{array}{l}\text { Optimal Pessary } \\
\text { Care: A Modified } \\
\text { Delphi Consensus } \\
\text { Study }\end{array}$ & $\begin{array}{l}\text { Técnica } \\
\text { Delphi } \\
\text { modificada } \\
\text { em quatro } \\
\text { rodadas e } \\
\text { incluiu uma } \\
\text { série de } \\
\text { pesquisas } \\
\text { on-line, duas } \\
\text { rodadas de } \\
\text { questionário } \\
\text { s on-line } \\
\text { anônimos, } \\
\text { e uma série } \\
\text { de reuniões } \\
\text { presenciais } \\
\text { em } \\
\text { conferências } \\
\text {. }\end{array}$ & $\begin{array}{lr}\text { Journal } & \text { of } \\
\text { Midwifery } \quad \& \\
\text { Women's Health }\end{array}$ & 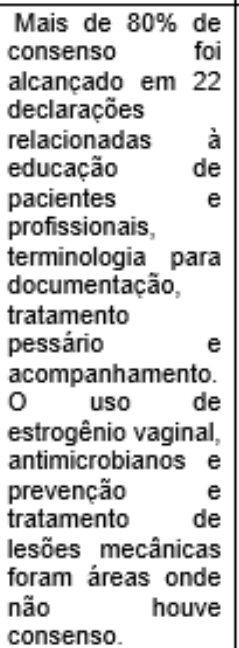 & $\begin{array}{l}\text { Prestadores } \\
\text { especializados em } \\
\text { pessários foram capazes } \\
\text { de desenvolver } \\
\text { recomendaçóes de } \\
\text { consenso para informar a } \\
\text { educação do prestador de } \\
\text { cuidados e os cuidados } \\
\text { clínicos onde } \\
\text { a base de evidências } \\
\text { permanece escassa. } \\
\text { Áreas em que não foi } \\
\text { alcançado consenso } \\
\text { informam a futura agenda } \\
\text { de pesquisa relacionada } \\
\text { ao pessário, necessária } \\
\text { para identificar } \\
\text { métodos pessários e } \\
\text { educacionais ótimos de } \\
\text { custo-beneficio para novos } \\
\text { prestadores de pessários. }\end{array}$ \\
\hline
\end{tabular}




\begin{tabular}{|c|c|c|c|c|c|c|}
\hline & & & & & $\begin{array}{l}\text { científica sobre o } \\
\text { fenômeno do } \\
\text { desenvolvimentod } \\
\text { a identidade de } \\
\text { gênero ainda é } \\
\text { limitada. }\end{array}$ & \\
\hline 2018 & $\begin{array}{l}\text { GONCALVE } \\
\text { S, } \\
\text { R.BRIGAGÃ } \\
\text { O, J. I. M. } \\
\text { SOARES, G. } \\
\text { C. F. S. }\end{array}$ & $\begin{array}{l}\text { STUDY CIRCLES } \\
\text { IN HOSPITALS' } \\
\text { OBSTETRICS } \\
\text { CENTERS AS A } \\
\text { TEACHINGLEAR } \\
\text { NING } \\
\text { STRATEGY IN } \\
\text { MIDWIFERY } \\
\text { EDUCATION }\end{array}$ & $\begin{array}{l}\text { Círculo de } \\
\text { estudos }\end{array}$ & Midwifery & $\begin{array}{l}\text { Os alunos } \\
\text { aprenderam muito } \\
\text { com o uso dos } \\
\text { círculos de estudo } \\
\text { durante o } \\
\text { treinamento } \\
\text { clínico. Ao } \\
\text { preparar o } \\
\text { tópicos para } \\
\text { discussâo, eles } \\
\text { aprenderam a } \\
\text { traduzir literatura } \\
\text { acadêmica } \\
\text { baseada em } \\
\text { evidências em } \\
\text { linguagem mais } \\
\text { simples } \\
\text { para que todos os } \\
\text { profissionais de } \\
\text { maternidade } \\
\text { pudessem } \\
\text { entendê-lo e } \\
\text { discuti-lo }\end{array}$ & $\begin{array}{l}\text { Promover a discussão } \\
\text { aberta entre diferentes } \\
\text { profissionais sobre } \\
\text { práticas alternativas que, } \\
\text { com boa facilitação, } \\
\text { proporcionam um } \\
\text { ambiente de escuta } \\
\text { para outros, vínculo entre } \\
\text { os participantes e a } \\
\text { melhoria da tomada de } \\
\text { decisâo compartilhada. }\end{array}$ \\
\hline 2018 & $\begin{array}{l}\text { JOHNSON, } \\
\text { S.R. }\end{array}$ & $\begin{array}{l}\text { Foreword: Caring } \\
\text { for Lesbians, } \\
\text { Bisexual Women, } \\
\text { Transgender, and } \\
\text { Gender } \\
\text { Nonconforming } \\
\text { People. }\end{array}$ & $\begin{array}{l}\text { Revisão } \\
\text { sistemática } \\
\text { de literatura }\end{array}$ & $\begin{array}{l}\text { CLINICAL } \\
\text { OBSTETRICS } \\
\text { AND } \\
\text { GYNECOLOGY }\end{array}$ & $\begin{array}{l}\text { A pesquisa com } \\
\text { relação à saúde } \\
\text { lésbica e bissexual } \\
\text { é um campo } \\
\text { maduro de } \\
\text { investigação, } \\
\text { tendo progredido } \\
\text { de relatos de } \\
\text { casos e pesquisas } \\
\text { para análise de } \\
\text { dados } \\
\text { populacionais. }\end{array}$ & $\begin{array}{l}\text { Recomendações para a } \\
\text { cuidados da saúde LGBTQ } \\
\text { estão disponiveis em } \\
\text { vários fontes. Entre estes } \\
\text { estão o Instituto de } \\
\text { Medicina, os Centros de } \\
\text { Controle de Doenças, } \\
\text { Comissão Mista e Pessoas } \\
\text { Saudáveis 2020. O Colégio } \\
\text { Americano de Obstetras e } \\
\text { Ginecologistas oferece } \\
\text { pareceres do comitê sobre } \\
\text { como cuidar de lésbicas e } \\
\text { mulheres bissexuais e } \\
\text { pessoas trans, incluindo } \\
\text { adolescentes. }\end{array}$ \\
\hline 2018 & $\begin{array}{l}\text { SOUSA, D. } \\
\text { M. N. N. } \\
\text { CAROLINA, } \\
\text { A. CHAGAS, } \\
\text { M. A. A. } \\
\text { VASCONCE } \\
\text { LOS, C. T. } \\
\text { M. STEIN, A. } \\
\text { T. ORIÁ, M. } \\
\text { O. B. }\end{array}$ & $\begin{array}{l}\text { Development of a } \\
\text { clinical protocol for } \\
\text { detection of } \\
\text { cervical cancer } \\
\text { precursor lesions }\end{array}$ & $\begin{array}{l}\text { Pesquisa de } \\
\text { validação de } \\
\text { tecnologia }\end{array}$ & $\begin{array}{l}\text { REVISTA } \\
\text { LATINO- } \\
\text { AMERICANA } \\
\text { DE } \\
\text { ENFERMAGEM }\end{array}$ & $\begin{array}{l}\text { A diretriz clínica } \\
\text { estudada traz } \\
\text { vantagens } \\
\text { tecnológicas } \\
\text { inovações no } \\
\text { rastreamento de } \\
\text { lesões que } \\
\text { causar câncer } \\
\text { cervical, como } \\
\text { cervicografia } \\
\text { digital e } \\
\text { colposcopia }\end{array}$ & $\begin{array}{l}\text { Recomenda-se a } \\
\text { realização de estudo } \\
\text { clínico para analisar o } \\
\text { impacto e implementação } \\
\text { de testes de rastreamento } \\
\text { e verificar a relação custo- } \\
\text { efetividade do uso desta } \\
\text { clínica para } \\
\text { implementação na rotina } \\
\text { dos serviços de saúde, }\end{array}$ \\
\hline 2018 & $\begin{array}{l}\text { FUGANTI, } \\
\text { C. C. T. } \\
\text { MARTINEZ, } \\
\text { E. Z. } \\
\text { GALVÃO, C. } \\
\text { M. }\end{array}$ & $\begin{array}{l}\text { Effect r of } \\
\text { preheating on the } \\
\text { maintenancer of } \\
\text { body temperature } \\
\text { in surgical } \\
\text { patients: a } \\
\text { randomized } \\
\text { clinical trial }\end{array}$ & $\begin{array}{l}\text { Ensaio } \\
\text { clínico } \\
\text { randomizad } \\
\text { o não cego. }\end{array}$ & $\begin{array}{l}\text { REVISTA } \\
\text { LATINO- } \\
\text { AMERICANA } \\
\text { DE } \\
\text { ENFERMAGEM }\end{array}$ & 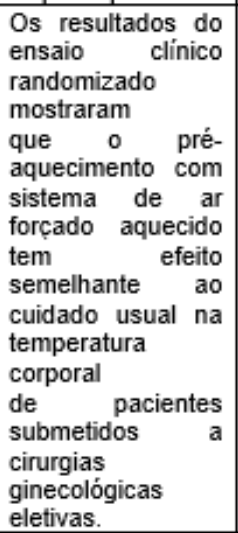 & Não se aplica \\
\hline
\end{tabular}




\begin{tabular}{|c|c|c|c|c|c|c|}
\hline 2018 & $\begin{array}{l}\text { NISLY, N. L. } \\
\text { IMBOREK, } \\
\text { K.L. } \\
\text { MILLER, M. } \\
\text { L. } \\
\text { KALISZEWS } \\
\text { KI, S. D. } \\
\text { WILLIAMS, } \\
\text { R. M. M. } \\
\text { KRASOWS } \\
\text { KI, M. D. }\end{array}$ & $\begin{array}{l}\text { Unique Primary } \\
\text { Care Needs of } \\
\text { Transgender and } \\
\text { Gender Non- } \\
\text { Binary People }\end{array}$ & $\begin{array}{l}\text { Estudo } \\
\text { Descritivo }\end{array}$ & $\begin{array}{l}\text { CLINICAL } \\
\text { OBSTETRICS } \\
\text { AND } \\
\text { GYNECOLOGY }\end{array}$ & $\begin{array}{l}\text { A população } \\
\text { transgênero } \\
\text { necessita de } \\
\text { vários cuidados de } \\
\text { saúde como para } \\
\text { o papanicolaou, } \\
\text { HPV, HIV, } \\
\text { cuidados pós } \\
\text { cirurgias de } \\
\text { afirmação sexual, } \\
\text { prevenção de } \\
\text { gravidez não } \\
\text { desejada, câncer } \\
\text { de mama, entre } \\
\text { outros. } \\
\end{array}$ & $\begin{array}{l}\text { Os profissionais de saúde } \\
\text { devem buscar o } \\
\text { atendimento integral, } \\
\text { acolhedora e inclusiva de } \\
\text { pacientes transgeneros, } \\
\text { devem realizar os } \\
\text { cuiadados necessários } \\
\text { como os cuidados } \\
\text { primários. } \\
\text { terminologia correta à essa } \\
\text { população e ter } \\
\text { conhecimento } \\
\text { desenvolvido sobre o } \\
\text { tema. }\end{array}$ \\
\hline 2018 & $\begin{array}{l}\text { JIANG, D. } \\
\text { WITTEN, J. } \\
\text { BRLI, } \\
\text { DUGI III, D. }\end{array}$ & $\begin{array}{l}\text { Does Depth } \\
\text { Matter? Factors } \\
\text { Affecting Choice of } \\
\text { Vulvoplasty Over } \\
\text { Vaginoplasty as } \\
\text { Gender-Affirming } \\
\text { Genital Surgery for } \\
\text { Transgender } \\
\text { Women }\end{array}$ & $\begin{array}{l}\text { Revisão } \\
\text { integrativa }\end{array}$ & $\begin{array}{l}\text { THE JOURNAL } \\
\text { OF SEXUAL } \\
\text { MEDICINE }\end{array}$ & $\begin{array}{l}486 \text { pacientes } \\
\text { foram atendidos } \\
\text { para cirurgia de } \\
\text { afirmação sexual } \\
\text { sendo } 396 \\
\text { solicitantes de } \\
\text { vaginoplastia e } 39 \\
\text { pacientes } \\
\text { solicitantes de } \\
\text { vulvoplastia. } 93 \% \\
\text { dos pacientes } \\
\text { operados } \\
\text { mostraram } \\
\text { satisfação da } \\
\text { vulvoplastia }\end{array}$ & $\begin{array}{l}\vec{E} \text { necessário que os } \\
\text { profissionais de saúde } \\
\text { envolvidos na cirurgia de } \\
\text { afirmação de sexo façam a } \\
\text { orientação necessária para } \\
\text { o paciente. }\end{array}$ \\
\hline 2018 & COLLEN, M. & $\begin{array}{l}\text { Marriage and } \\
\text { Family Building } \\
\text { Equality for } \\
\text { Lesbian, Gay, } \\
\text { Bisexual, } \\
\text { Transgender, } \\
\text { Queer, Intersex, } \\
\text { Asexual, and } \\
\text { Gender } \\
\text { Nonconforming } \\
\text { Individuals }\end{array}$ & Descritivo & $\begin{array}{l}\text { ACOG } \\
\text { COMMITTEE } \\
\text { OPNION }\end{array}$ & $\begin{array}{l}\text { Casais LGBTQIA } \\
\text { com filhos } \\
\text { encontram } \\
\text { dificuldades no } \\
\text { acesso à saúde } \\
\text { de sua família e } \\
\text { para seu } \\
\text { crescimento por } \\
\text { questões legais, } \\
\text { discriminação e } \\
\text { por profissionais } \\
\text { de saúde que se } \\
\text { negam a realizar o } \\
\text { serviço de forma } \\
\text { igualitária. Casais } \\
\text { que encontram } \\
\text { essas barreiras } \\
\text { são mais } \\
\text { propensos a } \\
\text { adquirir depressão } \\
\text { e aumento de } \\
\text { estresse, ou seja, } \\
\text { questões como } \\
\text { casamento e } \\
\text { constituição } \\
\text { familiar afetam } \\
\text { diretamente na } \\
\text { qualidade da } \\
\text { saúde das } \\
\text { pessoas } \\
\text { envolvidas. }\end{array}$ & $\begin{array}{l}\text { Deve ser feito a } \\
\text { capacitação para lidar com } \\
\text { pessoas LGBTQIA para o } \\
\text { acesso à saúde } \\
\text { reprodutiva, trabalhar para } \\
\text { a erradicação da } \\
\text { discriminação, apoiar e } \\
\text { incentivar pesquisas sobre } \\
\text { o tema e ao acesso à } \\
\text { saúde desta população } \\
\text { assim como questões de } \\
\text { políticas de saúde. }\end{array}$ \\
\hline 2018 & $\begin{array}{l}\text { LEARMONT } \\
\text { H, C. } \\
\text { VILORIA, R. } \\
\text { LAMBERT, } \\
\text { C. } \\
\text { GOLDHAM } \\
\text { MER, H. } \\
\text { KEUROGHL } \\
\text { IAN, A. S. }\end{array}$ & $\begin{array}{l}\text { Barriers to } \\
\text { insurance } \\
\text { coverage for } \\
\text { transgender } \\
\text { patients }\end{array}$ & Descritivo & $\begin{array}{l}\text { American } \\
\text { Journal of } \\
\text { Obstetrics \& } \\
\text { Gynecology }\end{array}$ & $\begin{array}{l}\text { Os sistemas de } \\
\text { registro de } \\
\text { pacientes não são } \\
\text { aptos para o } \\
\text { acolhimento de } \\
\text { transgêneros, pois } \\
\text { colocam o sexo da } \\
\text { qual foram } \\
\text { designados ao } \\
\text { nascer trazendo } \\
\text { desconforto e } \\
\text { preconceito, além } \\
\text { de não haver a } \\
\text { informacão se há }\end{array}$ & $\begin{array}{l}\text { Apresentar nos sistemas } \\
\text { de registro o sexo de } \\
\text { nascimento, } \\
\text { designado, informações } \\
\text { importantes como a } \\
\text { presença de cérvix. Maior } \\
\text { viabilidade de auxílio } \\
\text { necessário a essa } \\
\text { população, maior acesso à } \\
\text { saúde, r cuidados } \\
\text { obstétricos, ginecológicos } \\
\text { e de prevenção, educar } \\
\text { profissionais da área da } \\
\text { saúde à utilizacão correta }\end{array}$ \\
\hline
\end{tabular}




\begin{tabular}{|c|c|c|c|c|c|c|}
\hline & & & & & $\begin{array}{l}\text { presença de } \\
\text { cérvix. Segundo a } \\
\text { pesquisa de } \\
27000 \\
\text { transgêneros } \\
\text { entrevistados, um } \\
\text { terço deles foram } \\
\text { assediados } \\
\text { quando } \\
\text { procuravam } \\
\text { atendimento }\end{array}$ & $\begin{array}{l}\text { de terminologias próprias, } \\
\text { triagem de saúde e } \\
\text { aconselhamento sobre } \\
\text { saúde e fertilidade. }\end{array}$ \\
\hline 2019 & $\begin{array}{l}\text { SANTOS, M. } \\
\text { A. SOUZA, } \\
\text { R. S. LARA, } \\
\text { L. A. S. } \\
\text { RISK, E. N. } \\
\text { OLIVEIRA, } \\
\text { W. A. A. } \\
\text { ALEXANDR } \\
\text { E, V. } \\
\text { OLIVEIRA- } \\
\text { CARDOSO, } \\
\text { E. A. }\end{array}$ & $\begin{array}{l}\text { Transexualidade, } \\
\text { ordem médica,e } \\
\text { política de saúde: } \\
\text { controle nosmativo } \\
\text { do processo } \\
\text { transexualizador } \\
\text { no Brasil }\end{array}$ & $\begin{array}{l}\text { Análise } \\
\text { documental }\end{array}$ & $\begin{array}{l}\text { PERIÓDICOS } \\
\text { ELETRÖNICOS } \\
\text { EM } \\
\text { PSICOLOGIA }\end{array}$ & $\begin{array}{l}\text { Foram } \\
\text { encontrados } 14 \\
\text { registros de } \\
\text { documentos cujo } \\
\text { critério de inclusão } \\
\text { se enquadrava na } \\
\text { regulamentação } \\
\text { da prescrição de } \\
\text { hormonioterapia } \\
\text { ou da cirurgia de } \\
\text { transgenitalização } \\
\text { em pessoas } \\
\text { transexuais. }\end{array}$ & $\begin{array}{l}\text { Ainda que seja lenta sua } \\
\text { implantação, os avanços } \\
\text { foram consideráveis. No } \\
\text { entanto, atualmente paira } \\
\text { um desafio à manutenção } \\
\text { e potencialização do PrTr } \\
\text { (Processo } \\
\text { Transexualizador) no SUS, } \\
\text { com a possibilidade de } \\
\text { retrocesso imposta pela } \\
\text { política ultraconservadora } \\
\text { que tem pautado a atuação } \\
\text { do executivo e legislativo } \\
\text { no país a partir de janeiro } \\
\text { de } 2019 \text {. }\end{array}$ \\
\hline 2019 & $\begin{array}{l}\text { DENDRINO } \\
\text { S, M. L. } \\
\text { BUDRYS, N. } \\
\text { M. } \\
\text { SANGHA, } \\
\text { R. }\end{array}$ & $\begin{array}{l}\text { Addressing the } \\
\text { Needs of } \\
\text { Transgender } \\
\text { Patients: How } \\
\text { Gynecologists Can } \\
\text { Partner in Their } \\
\text { Care. }\end{array}$ & $\begin{array}{l}\text { Pesquisa } \\
\text { exploratória } \\
\text { quantitativa/ } \\
\text { qualitativa }\end{array}$ & $\begin{array}{l}\text { Obstetrical and } \\
\text { Gynecological } \\
\text { Survey }\end{array}$ & $\begin{array}{l}\text { São descritos } \\
\text { vários aspectos do } \\
\text { atendimento } \\
\text { ginecológico de } \\
\text { pacientes trans, } \\
\text { incluindo exames } \\
\text { de manutenção da } \\
\text { saúde e triagem } \\
\text { de câncer, terapia } \\
\text { de reposição } \\
\text { hormonal, } \\
\text { histerectomia e } \\
\text { salpingo- } \\
\text { ooforectomia, } \\
\text { encaminhamento } \\
\text { e colaboração } \\
\text { com a equipe de } \\
\text { atendimento do } \\
\text { paciente. }\end{array}$ & $\begin{array}{l}\text { Realizar a assistência à } \\
\text { saúde de forma holística, } \\
\text { com qualidade e } \\
\text { integralidade. Utilizar } \\
\text { linguagem própria, apoio } \\
\text { social e educação da } \\
\text { população e de } \\
\text { profissionais e futuros } \\
\text { profissionais da saúde }\end{array}$ \\
\hline 2019 & $\begin{array}{l}\text { VINEKAR, } \\
\text { K. RUSH, S. } \\
\text { K. CHIANG, } \\
\text { S. SCHIFF, } \\
\text { M. A. }\end{array}$ & $\begin{array}{l}\text { Educating } \\
\text { Obstetrics and } \\
\text { Gynecology } \\
\text { Residents on } \\
\text { Transgender } \\
\text { Patients A Survey } \\
\text { of Program } \\
\text { Directors }\end{array}$ & $\begin{array}{l}\text { Pesquisa } \\
\text { transversal }\end{array}$ & $\begin{array}{l}\text { OBSTETRICS \& } \\
\text { GYNECOLOGY }\end{array}$ & $\begin{array}{l}\text { Metade dos } \\
\text { programas de } \\
\text { residência de } \\
\text { ginecologia e } \\
\text { obstetrícia } \\
\text { apresentaram a } \\
\text { educação sobre } \\
\text { transgêneros, por } \\
\text { conta disso há } \\
\text { uma falta de } \\
\text { currículo } \\
\text { abrangente, } \\
\text { financiamento e } \\
\text { corpo docente } \\
\text { capacitado para a } \\
\text { educação sobre } \\
\text { transgêneros e o } \\
\text { acesso à saúde } \\
\text { ginecológica e } \\
\text { obstétrica. }\end{array}$ & $\begin{array}{l}\text { É necessário que haja } \\
\text { uma maior capacitação de } \\
\text { docentes, residentes e } \\
\text { profissionais da área de } \\
\text { saúde sobre o } \\
\text { atendimento do público } \\
\text { transgênero e seu auxílio } \\
\text { de saúde em ginecologia e } \\
\text { obstetrícia. }\end{array}$ \\
\hline
\end{tabular}

Fonte: Dados da pesquisa, 2020.

Observou-se, na fase de revisão integrativa, correspondente à teorização dentro do fluxo do Arco de Maguerez, que a maioria dos artigos encontrados era datado de 2018 e 2019, conferindo modernidade e frescor ao compilado, bem como o tipo de pesquisa 
utilizada pelos mesmos foi em sua esmagadora maioria de pesquisa exploratória descritiva transversal.

Além da articulação de métodos optou-se ainda, durante a fase de hipótese de solução, por abrir o leque de sistemas taxonômicos usados dentro do Processo de Enfermagem, especificamente durante o diagnóstico de enfermagem, etapa imprescindível à construção da terapêutica e às prescrições de enfermagem. (COFEN, 2009)

Entre esses sistemas, foram adotadas a taxonomia NANDA, largamente utilizada nos EUA e no Brasil e o sistema CIPE®, de origem europeia, mais recente e menos utilizados pela enfermagem brasileira, nem por isso menos importante, isto sim, até mais abrangente e proporcionador de autonomia e sincronicidade no entendimento $\mathrm{e}$ assimilação dos termos empregados. Ambos são definidos como sistemas multiaxiais, com metodologias peculiares, que apresentam diferenças básicas de utilização, mas que guardam entre si estreitas relações e similaridades. (NANDA, 2018-2020; CIPE®, 2020)

Os principais e mais recorrentes enunciados diagnósticos de enfermagem encontrados na realidade das comunidades trans que buscam assistência de enfermagem na ABS foram:

Quadro 2- Enunciados diagnósticos de enfermagem atribuídos às etapas de hipóteses de solução e aplicação à realidade na metodologia da problematização, conforme taxonomias NANDA e CIPE

\begin{tabular}{|l|l|}
\hline NANDA & CIPE \\
\hline $\begin{array}{l}\text { Comportamento de saúde propenso a } \\
\text { risco }\end{array}$ & Abuso de substâncias \\
\hline Insônia & Angústia espiritual e moral \\
\hline Autonegligência & Ansiedade \\
\hline Medo & Atitude familiar conflituosa \\
\hline
\end{tabular}




\begin{tabular}{|l|l|}
\hline $\begin{array}{l}\text { Risco de dignidade humana } \\
\text { comprometida }\end{array}$ & Déficit de autocuidado \\
\hline $\begin{array}{l}\text { Risco de distúrbio da identidade pessoal } \\
\text { Risco de síndrome de stress por } \\
\text { mudança }\end{array}$ & \begin{tabular}{l} 
Falta de apoio familiar \\
\hline Risco de sofrimento espiritual
\end{tabular} \\
& $\begin{array}{l}\text { Enfrentamento } \\
\text { prejudicado }\end{array}$ \\
\hline & Risco de infecção \\
\hline & Risco de solidão \\
\hline & Não adesão a sistema diagnóstico \\
\hline
\end{tabular}

Fonte: Dados da pesquisa, 2020.

\section{DISCUSSÃO}

Os artigos abordados nesta revisão integrativa demonstraram a visão da assistência de enfermagem à população transgênero e torna flagrante a dificuldade de manejo por parte de profissionais e serviços de saúde, considerando as diversidades de gênero dos usuários.

O presente estudo destacou uma realidade constante dos atendimentos, desde a triagem até a consulta ginecológica. Serviços que por vezes não encontram a solução requerida por sua especificidade. Diante deste cenário, essa população enfrenta o preconceito, a discriminação e o despreparo profissional por parte daqueles a quem cabe oferecer os cuidados necessários, o que os leva ao absenteísmo recorrente e os vitimizando múltiplas vezes.

Durante a investigação bibliográfica é perceptível a escassez de artigos que se relacionem com o tema designado para o público transgênero, especialmente no tocante ao atendimento de enfermagem, o que se traduz em um grande desafio para a sociedade e profissionais de saúde: tornar essa temática tão natural quanto realmente é para aqueles que a vivenciam. 
Os determinantes sociais a que essa população está exposta, proporcionam a exclusão dos diversos cenários de exercício da cidadania e impossibilita a assistência integral e universal, alargando o abismo de iniquidades, seja pela necessidade de melhor capacitação profissional para atender o público transgênero, o que reflete uma fragilidade na formação profissional, seja pela não implementação de políticas de inclusão e fortalecimento das liberdades individuais. (BUSS E PELLEGRINI, 2007)

Sendo assim, faz-se necessário sensibilizar todas as esferas de governo e da sociedade para o respeito ao indivíduo como cidadão, independentemente de sua identidade de gênero, e a Enfermagem, em sua robustez científica e representatividade dentro das equipes de saúde, deve basear suas ações em conceitos sólidos e científicos, replicando-os através de procedimentos operacionais padrão, e não apenas de meras repetições empíricas.

\section{CONSIDERAÇÕES FINAIS}

Quando se busca a equidade no atendimento, tal qual preconiza o SUS, o primeiro passo para a construção de um alicerce robusto e confiável é a escolha de uma teoria de enfermagem que mediará o desenvolvimento do Processo de Enfermagem que atenda às necessidades de um público específico, no presente caso o público transgênero, conferindo-Ihe cientificidade e credibilidade acadêmicas. Esse estudo contou com as reflexões de Madeleine Leininger, por meio da sua teoria transcultural, cujos pressupostos principais defendem que a essência da enfermagem é o cuidado, e a essência da enfermagem transcultural é o cuidado a indivíduos de diversas heranças culturais, mediando o desenvolvimento de todo o Processo de Enfermagem. (LEININGER, 1997)

Encontramos em Madeleine M. Leininger, e sua teoria da transculturalidade, a chance e a inspiração para desenvolver um Processo de Enfermagem capaz, não só de respeitar, mas valorizar experiências e escolhas pessoais, tendo em vista que tal teoria defende que a Enfermagem é a ciência do cuidado, devendo enfocar não somente a relação Enfermeira/Cliente/Paciente, mas envolver e interagir com família, grupos, comunidades, culturas completas e instituições. 
A teoria da transculturalidade se nos mostrou adequada na construção de um Processo de Enfermagem condizente com as necessidades de respeito às diversidades por abordar explicitamente os sistemas de saúde, práticas da assistência, mudanças de padrões, promoção da saúde e manutenção da saúde em seu modelo, onde o enfermeiro nem sempre está adequadamente preparado para enfrentar essas diferenças culturais e suas respectivas influências no cuidar, ou então, que não a valorizam ou reconhecem como legítimas, e por sugerir três tipos de ações de enfermagem culturalmente congruentes com as crenças e valores dos clientes, sejam elas:

- Conservação/manutenção do cuidado cultural;

- Ajustamento/negociação do cuidado cultural;

- Repadronização/reestruturação do cuidado cultural.

Ainda que a teoria de Leininger tenha sido estruturada, inicialmente, a partir da antropologia e focando no respeito às diferentes culturas distribuídas geograficamente pelo globo e pelas diferentes comunidades e arranjos demográficos humanos, não há por que não estender seus ensinamentos e embasamentos às mais diferentes manifestações humanas, sejam elas culturais, comportamentais, sociais ou sexuais, afinal, quando se conhece e respeita a cultura, o hábito, a escolha do outro, é possível construir pontes e estabelecer vínculos, facilitando e humanizando, assim o atendimento.

Tendo em vista que a própria teorista defende a "Reestruturação Cultural do Cuidado" como modelos reconstruídos ou alterados para auxiliar o cliente a mudar os padrões de saúde ou de vida, de forma a tornar significativo ou congruente para ele próprio, podemos como enfermeiros nos apropriar dessa premissa para auxiliar os pacientes em sua busca por equilíbrio emocional, orgânico e social, e vislumbrar um futuro onde todos, não importando suas escolhas, cor, religião ou sexo, possam ser respeitados e tenham a sua dignidade e a autonomia sobre seus corpos e sua saúde intocados. Um futuro próximo, do qual a Enfermagem faz parte, e para o qual é imprescindível. 


\section{REFERÊNCIAS}

BOUMAN, Mark-Bram; SLUIS, Wouter B van Der; HAMSTRA, Leonora E van Woudenberg; BUNCAMPER, Marlon E; KREUKELS, Baudewijntje PC.; MEIJERINK, Wilhelmus JHJ; MULLENDER, Margriet G. Patient-Reported Esthetic and Functional Outcomes of Primary Total Laparoscopic Intestinal Vaginoplasty in Transgender Women With Penoscrotal Hypoplasia. The Journal Of Sexual Medicine, v. 13, n. 9, p. 1438-1444, 2016. Disponível em: (https://www.jsm.jsexmed.org/article/S17436095(16)30300-9/fulltext). Acesso em: 16/10/2020.

BRASIL, Senado Federal. Constituição da república federativa do Brasil. Brasília: Senado Federal, Centro Gráfico, 1988.

BRASIL. Ministério da Saúde. Portaria ํㅡㄴ.436, de 21 de setembro de 2017. Aprova a Política Nacional de Atenção Básica, estabelecendo a revisão de diretrizes para a organização da Atenção Básica, no âmbito do Sistema Único de Saúde (SUS). Brasília, DF: Ministério da Saúde, 2017.

BUSS, P. M.; PELLEGRINI FILHO, A. A saúde e seus determinantes sociais. Physis, Rio de Janeiro, v. 17, n. 1, p. 77-93, 2007.

DE ENFERMAGEM, Conselho Federal. Resolução COFEN n. 0564/2017 Aprova o novo Código de Ética dos Profissionais de Enfermagem. Presidente do Cofen Manoel Carlos Neri da Silva. 2017.

DE ENFERMAGEM, Conselho Federal. Resolução COFEN-358/2009. Dispõe sobre a sistematização da assistência de enfermagem-SAE nas instituições de saúde brasileiras. Brasília, 2009. Disponível em: (http: // www.portalcofen.gov). Acesso em: 05/06/2020.

DENDRINOS, Melina L. BUDRYS, Nicole M. SANGHA. Roopina. Addressing the Needs of Transgender Patients: How Gynecologists Can Partner in Their Care. Obstetrical \& gynecological survey, v. 74, n. 1, p. 33-39, 2019. Disponível 
em:(https:/journals.Iww.com/obgynsurvey/Abstract/2019/01000/Addressing_the_Nee ds_of_Transgender_Patients_How.18.aspx). Acesso em: 16/10/2020.

FUGANTI, Cibele Cristina Tramontini; MARTINEZ, Edson Zangiacomi; GALVÃO, Cristina Maria. Effect of preheating on the maintenance of body temperature in surgical patients: a randomized clinical trial. Revista Latino-Americana de Enfermagem, v. 26, p. 01-10, 2018. Disponível em: (https://www.scielo.br/scielo.php?pid=S0104$11692018000100366 \&$ script=sci_abstract\&tlng=pt). Acesso em 27/10/2020.

GRANT, Carolina. Bioética e Transexualidade: para além da patologização, uma questão de identidade de gênero. In: XIX Encontro Nacional do CONPEDI, 2010, Fortaleza. Anais do XIX Encontro Nacional do CONPEDI. Florianópolis: Fundação Boiteux, 2010, pp. 842-858.

MICHAELIS. Moderno Dicionário da Língua Portuguesa. São Paulo: Companhia Melhoramentos, 2015.

HERDMAN, T. Heather; KAMITSURU, Shigemi. Diagnósticos de enfermagem da NANDA: definições e classificação 2018-2020, $11^{\circ}$ edição. Porto Alegre: Artmed, 2018.

GARCIA, Telma Ribeir; COENEN, Amy M.; BARTZ, Claudia C. Classificação internacional para a prática de enfermagem $\mathrm{CIPE} \circledast{ }^{\circledR}$ : versão 2017. Porto Alegre: Artmed, 2018.

GONÇALVES, Roselane; BRIGAGÃO, Jacqueline Isaac Machado; SOARES, Glauce Cristine Ferreira. Study circles in hospitals' obstetrics centers as a teaching-learning strategy in midwifery education. Midwifery, v. 61, p. 42-44, 2018. Disponível em: (https://www.sciencedirect.com/science/article/abs/pii/S026661381830041X?via\%3Di hub). Acesso em: 14/11/2020.

HOOPER, Gwendolyn L.; ATNIP, Shanna; O'DELL, Katharine. Optimal Pessary Care: a modified delphi consensus study. Journal Of Midwifery \& Women'S Health, v. 62, 
n. $4, \quad$ p. 452-462, 2017. Disponível em:

(https://onlinelibrary.wiley.com/doi/abs/10.1111/jmwh.12624) Acesso em: 10/9/2020.

JIANG, David; WITTEN, Jonathan; BERLI, Jens; DUGI, Daniel. Does Depth Matter? Factors Affecting Choice of Vulvoplasty Over Vaginoplasty as Gender-Affirming Genital Surgery for Transgender Women. The Journal Of Sexual Medicine, v. 15, n. 6, p. 902-906, 2018. Disponível em: (https://www.jsm.jsexmed.org/article/S17436095(18)30267-4/fulltext) Acesso em: 07/07/2020.

LEININGER, Madeleine. Caring: An essential human need Detroit: Wayne state university press, p. 3-11, 1988.

JOHNSON, Susan R. Caring for Lesbians, Bisexual Women, Transgender, and Gender Nonconforming People. Clinical obstetrics and gynecology, v. 61, n. 4, p. 643-645, 2018.

Disponível

em:

(https://journals.Iww.com/clinicalobgyn/Citation/2018/12000/Foreword_Caring_for_L esbians,_Bisexual_Women,.2.aspx) Acesso em: 24/05/2020.

LEARMONTH, Claire; VILORIA, Rebekah; LAMBERT, Cei; GOLDHAMMER, Hilary; KEUROGHLIAN, Alex S. Barriers to insurance coverage for transgender patients. American Journal Of Obstetrics And Gynecology, v. 219, n. 3, p. 272.1272.4, 2018. Disponível em: (https://www.ajog.org/article/S0002-9378(18)303776/fulltext). Acesso em: 21/10/2020.

MCNICHOLAS, Colleen. Marriage and Family Building Equality for Lesbian, Gay, Bisexual, Transgender, Queer, Intersex, Asexual, and Gender Nonconforming Individuals. Obstetrics and Gynecology, v. 132, n. 2, p. 82-86, 2018. Disponível em: (https://www.acog.org/clinical/clinical-guidance/committeeopinion/articles/2018/08/marriage-and-family-building-equality-for-lesbian-gaybisexual-transgender-queer-intersex-asexual-and-gender-nonconformingindividuals). Acesso em: 30/10/2020. 
NICHOLSON, Linda. "Interpretando o gênero". Revista Estudos Feministas, v. 8, n. 2, $\quad$ p. $\quad 9-41, \quad 2000 . \quad$ Disponível em: (https://periodicos.ufsc.br/index.php/ref/article/view/11917). Acesso em: 31/08/2020.

NISLY, Nicole L.; IMBOREK, Katherine L.; MILLER, Michelle L.; KALISZEWSKI, Susan D.; WILLIAMS, Rachel M.; KRASOWSKI, Matthew D. Unique Primary Care Needs of Transgender and Gender Non-Binary People. Clinical Obstetrics And Gynecology, v. 61, n. 4, p. 674-686, 2018. Disponível em: (https://journals.Iww.com/clinicalobgyn/Abstract/2018/12000/Unique_Primary_Care_ Needs_of_Transgender_and.5.aspx). Acesso em: 28/10/2020.

OBEDIN-MALIVER, Juno. Time for OBGYNs to Care for People of All Genders. Journal Of Women'S Health, v. 24, n. 2, p. 109-111, 2015. Disponível em: (https://www.liebertpub.com/doi/10.1089/jwh.2015.1518?url_ver=Z39.882003\&rfr_id=ori:rid:crossref.org\&rfr_dat=cr_pub\%20\%200pubmed)Acesso em: 06/09/2020.

PETRY, Analídia Rodolpho. Mulheres transexuais e o Processo Transexualizador: experiências de sujeição, padecimento e prazer na adequação do corpo. Revista Gaúcha de Enfermagem, v. 36, n. 2, p. 70-75, 2015. Disponível em: (https://seer.ufrgs.br/RevistaGauchadeEnfermagem/article/view/50158). Acesso em: 24/10/2020.

POPADIUK, Gianna Schreiber; OLIVEIRA, Daniel Canavese; SIGNORELLI, Marcos Claudio. A Política Nacional de Saúde Integral de Lésbicas, Gays, Bissexuais e Transgêneros (LGBT) e o acesso ao Processo Transexualizador no Sistema Único de Saúde (SUS): avanços e desafios. Ciência \& Saúde Coletiva, v. 22, n. 5, p. 15091520, 2017. Disponível em: (https://www.scielo.br/scielo.php?pid=S1413$81232017002501509 \&$ script=sci_abstract\&tIng=pt). Acesso em: 21/09/2020.

SANTOS, Magda Guadalupe. SEMONE DE BEAUVOIR. "Não se nasce mulher, tornase mulher". Sapere Aude, Belo Horizonte, v. 1, n. 2, p. 108-122, 2010. Disponível em: 
(http://periodicos.pucminas.br/index.php/SapereAude/article/view/2081). Acesso em 14/08/2020.

SANTOS, Manoel Antônio dos; SOUZA, Ricardo Santos de; LARA, Lúcia Alves da Silva; RISK, Eduardo Name; OLIVEIRA, Wanderlei Abadio de; ALEXANDRE, Vinicius; OLIVEIRA-CARDOSO, Érika Arantes de. Transexualidade, ordem médica e política de saúde: controle normativo do processo transexualizador no brasil. Estudos Interdisciplinares em Psicologia, v. 10, n. 1, p. 03-17, 2019. Disponível em: (http://pepsic.bvsalud.org/scielo.php?script=sci_arttext\&pid=S223664072019000100002). Acesso em: 21/09/2020.

SILVA, Carla Marins; SILVA, Bárbara Vilela Nazário da; OLIVEIRA, Daniela Soares de; OLIVEIRA, Vanessa, Silva de; VARGENS, Octavio Muniz da Costa. Consulta ginecológica e a relação profissional-cliente: perspectiva de usuárias. Revista Enfermagem UERJ, v. 24, n. 4, p. 23671, 2016. Disponível em: (https://www.epublicacoes.uerj.br/index.php/enfermagemuerj/article/view/23671). Acesso em 14/10/2020.

SILVA, Carolina de Mendonça Coutinho e; VARGENS, Octavio Muniz da Costa. Woman experiencing gynecologic surgery: coping with the changes imposed by surgery. Revista Latino-Americana de Enfermagem, v. 24, p. 01-08, 2016. Disponível em:

(https://www.scielo.br/scielo.php?pid=S0104$11692016000100403 \&$ script=sci_abstract\&tIng=pt). Acesso em 15/09/2020.

SOUSA, Deise Maria do Nascimento; CHAGAS, Ana Carolina Maria Araújo; VASCONCELOS, Camila Teixeira Moreira; STEIN, Airton Tetelbom; ORIÁ, Mônica Oliveira Batista. Development of a clinical protocol for detection of cervical cancer precursor lesions. Revista Latino-Americana de Enfermagem, v. 26, p. 01-09, 2018. Disponível em: (https://www.scielo.br/scielo.php?script=sci_arttext\&pid=S010411692018000100316). Acesso em 15/09/2020.

SOUZA, Juliana Caldas de; LIMA, Juliana de Oliveira Roque e; MUNARI, Denize Bouttelet; ESPERIDIÃO, Elizabeth. Ensino do cuidado humanizado: evolução e 
tendências da produção científica. Revista Brasileira de Enfermagem, v. 61, n. 6, p. 878-882, 2008. Disponível em: (https://www.scielo.br/scielo.php?pid=S003471672008000600014\&script=sci_abstract\&tIng=pt). Acesso em: 15/10/2020.

SPIZZIRRII, Giancarlo. Disforia de gênero em indivíduos transexuais adultos: aspectos clínicos e epidemiológicos. Diagn, Tratamento, v. 1060, p. 970, 2017. Disponível em: (https://docs.bvsalud.org/biblioref/2017/03/832448/rdt_v22n1_4548.pdf). Acesso em 19/09/2020.

SPIZZIRRI, Giancarlo. Aspectos genéticos relacionados ao transexualismo. Diagn, tratamento, v. 20, n. 2, p. 76-9, 2015. Disponível em: (http://www.apm.org.br/publicacoes/rdt_online/RDT_v20n2.pdf\#page=30). Acesso em 21/09/2020.

UNGER, Cécile A. Care of the Transgender Patient: a survey of gynecologists' current knowledge and practice. Journal Of Women'S Health, v. 24, n. 2, p. 114-118. 2015. Disponível em: (https://www.liebertpub.com/doi/10.1089/jwh.2014.4918?url_ver=Z39.882003\&rfr_id=ori:rid:crossref.org\&rfr_dat=cr_pub\%20\%200pubmed). Acesso em 15/09/2020.

VINEKAR, Kavita; RUSH, Shannon K.; CHIANG, Seine; SCHIFF, Melissa A. Educating Obstetrics and Gynecology Residents on Transgender Patients. Obstetrics \& Gynecology, v. 133, n. 4, p. 691-699, abr. 2019. Disponível em:(https:/journals.Iww.com/greenjournal/Abstract/2019/04000/Educating_Obstetrics _and_Gynecology_Residents_on.15.aspx) Acesso em: 15/09/2020.

ZAVLIN, Dmitry et al. Male-to-female sex reassignment surgery using the combined vaginoplasty technique: satisfaction of transgender patients with aesthetic, functional, and sexual outcomes. Aesthetic plastic surgery, v. 42, n. 1, p. 178-187, 2018. Disponível em: (https://link.springer.com/article/10.1007/s00266-017-1003-z). Acesso em 14/07/2020.

Enviado: Dezembro, 2020. 
Aprovado: Dezembro, 2020. 